\title{
Repetitive stimulation of phrenic nerves in myasthenia gravis
}

\author{
A Mier, C Brophy, J Moxham, M Green
}

\begin{abstract}
Background In the investigation of patients with myasthenia gravis, repetitive supramaximal stimulation of an affected peripheral nerve is commonly performed to detect abnormal transmission at the neuromuscular junction. A study was undertaken to determine whether abnormal transmission could similarly be detected during stimulation of the phrenic nerves.

Methods The phrenic nerves were stimulated supramaximally with surface electrodes in 13 patients with myasthenia gravis and in 16 control subjects (six control patients with diaphragmatic weakness but not with myasthenia and ten normal subjects). The amplitude of diaphragm muscle action potentials was measured with surface electrodes during phrenic nerve stimulation at frequencies of 1-5 Hz for 3-4 seconds.
\end{abstract}

Results In five patients with myasthenia gravis, a significant decrement (15-43\% decrease) occurred in the amplitude of diaphragm muscle action potential during stimulation at $3 \mathrm{~Hz}$. When stimulation frequency was reduced to $1 \mathrm{~Hz}$, diaphragm muscle action potentials returned to their original amplitude within 4-5 seconds. The decrement in the amplitude of the diaphragm muscle action potential was reduced temporarily in three of four patients after the administration of intravenous edrophonium chloride (Tensilon). There was no significant change ( $<10 \%$ decrease) in the amplitude of diaphragm muscle action potentials during stimulation at increased frequencies either in the 16 control subjects or in eight of the patients with myasthenia gravis. Conclusion A significant reduction in the amplitude of diaphragm muscle action potential occurred in five of 13 patients with myasthenia gravis during phrenic nerve stimulation at $3 \mathrm{~Hz}$ but in none of the control subjects. This may be a useful and non-invasive method for identifying patients with myasthenia gravis in whom weakness of the diaphragm is suspected.

Myasthenia gravis is an autoimmune disorder of the neuromuscular junction which results in a reduced number of acetylcholine receptors on the postsynaptic membrane. Clinically it is characterised by development of weakness after exercise and a tendency to recover after rest. Respiratory insufficiency requiring ventilatory support is an important and serious complication of myasthenia gravis, which may be unsuspected until a late stage. The degree of dyspnoea is not always a reliable indication of the severity of respiratory muscle weakness. A simple technique to demonstrate diaphragmatic muscle weakness would be a valuable indicator of those patients at risk of developing respiratory problems.

Repetitive supramaximal stimulation of an affected peripheral nerve at increased frequencies is commonly performed as a method of detecting abnormal transmission at the neuromuscular junction in patients with suspected myasthenia gravis. As a standard procedure, compound muscle action potentials are recorded with surface electrodes from at least three muscles during stimulation at frequencies of 1-5 Hz. ${ }^{1}$ Patients with myasthenia gravis affecting the relevant muscle show a decrement in the amplitude of the compound muscle action potential of more than $10 \%$ when the fifth response is compared with the first. We have performed a study to determine whether a similar phenomenon could be shown for the diaphragm.

\section{Methods}

Studies were performed on 13 patients with myasthenia gravis in whom the disease was clinically active and who were under the care of doctors in a clinic specialising in myasthenia gravis. The diagnosis of myasthenia was based on a combination of history of fatiguable muscle weakness, clinical examination, electromyograms, and nerve conduction studies. Clinical staging was performed on the day of the studies and is summarised in table 1. All patients complained of exertional dyspnoea. Eleven patients were non-smokers and two were ex-smokers of 20 cigarettes per day. Their mean (SD) forced expiratory volume in one second was $85.4(21.6) \%$ predicted. Antiacetylcholine receptor antibodies were present in all patients except two (patients 2 and 3 ) and seven patients had undergone thymectomy (patients 4, 5, 6, 9, 10,12, and 13). All patients except 2, 5, and 13 were taking anticholinesterase drugs; in addition patient 1 was taking prednisolone and patients 8,10 , and 12 were taking both prednisolone and azathioprine. The diagnosis of myasthenia in patient 13 was confirmed after these studies were performed and so he was having no treatment at the time of investigation. Patients 4, 6, 9, 10, 12, and 13 had required ventilation in the past. 
Table 1 Clinical features of patients with myasthenia gravis

\begin{tabular}{|c|c|c|c|c|c|c|c|c|c|c|c|c|c|}
\hline \multirow[b]{2}{*}{ Patient } & \multirow{2}{*}{$\begin{array}{l}\text { Age } \\
\text { (years) }\end{array}$} & \multirow[b]{2}{*}{ Sex } & \multirow{2}{*}{$\begin{array}{l}\text { Height } \\
(\mathrm{cm})\end{array}$} & \multirow{2}{*}{$\begin{array}{l}\text { Weight } \\
\text { (kg) }\end{array}$} & \multirow{2}{*}{$\begin{array}{l}\text { Duration } \\
\text { of } \\
\text { myasthenia }\end{array}$} & \multirow{2}{*}{$\begin{array}{l}\text { Duration } \\
\text { of } \\
\text { dyspnoea }\end{array}$} & \multirow{2}{*}{$\begin{array}{l}\text { Clinical } \\
\text { stage }^{\star}\end{array}$} & \multirow{2}{*}{$\begin{array}{l}\text { Grade } \\
\text { of } \\
\text { dyspnoeat }\end{array}$} & \multirow{2}{*}{$\begin{array}{l}\text { Sniff } \\
P d i \\
\left(\mathrm{CmH}_{2} \mathrm{O}\right)\end{array}$} & \multicolumn{2}{|c|}{$\begin{array}{l}\text { Conduction } \\
\text { time of phrenic } \\
\text { nerve (ms }{ }^{\ddagger}\end{array}$} & \multicolumn{2}{|c|}{$\begin{array}{l}\text { Decrement of } \\
D M A P(\%)\end{array}$} \\
\hline & & & & & & & & & & Right & Left & Right & Left \\
\hline 1 & 63 & $\mathbf{F}$ & 160 & 73 & 3 years & 3 months & IV & 4 & 104 & 8.0 & 9.0 & 3 & 0 \\
\hline 2 & 52 & $\mathbf{M}$ & 180 & 83 & 16 years & 2 years & IIA & 2 & 132 & $8 \cdot 5$ & 8.5 & 7 & 0 \\
\hline 3 & 20 & $\mathbf{F}$ & 168 & 58 & 2 years & 6 months & IIA & 2 & 95 & $6 \cdot 0$ & 6.5 & 0 & 0 \\
\hline 4 & 34 & $\mathbf{F}$ & 173 & 90 & 4 years & 3 months & IIA & 3 & 95 & $7 \cdot 5$ & $7 \cdot 5$ & 43 & 25 \\
\hline 5 & 52 & $\mathbf{F}$ & 150 & 54 & 45 years & 3 years & IIB & 3 & 95 & 6.0 & 6.0 & 0 & 5 \\
\hline 6 & 54 & $\mathbf{F}$ & 161 & 57 & 6 years & 6 weeks & IIB & 3 & 40 & $8 \cdot 0$ & 8.0 & 26 & 30 \\
\hline 7 & 52 & $\mathbf{F}$ & 168 & 70 & 5 months & 4 months & IIA & 3 & 75 & 9.0 & 8.7 & 19 & 9 \\
\hline 8 & 43 & $\mathbf{F}$ & 168 & 70 & 26 years & 1 year & IIB & 2 & 68 & $7 \cdot 0$ & $7 \cdot 0$ & 0 & 0 \\
\hline 9 & 32 & $\mathrm{~F}$ & 167 & 60 & 14 years & 1 year & IIA & 2 & 65 & $6 \cdot 5$ & $7 \cdot 5$ & 5 & 15 \\
\hline 10 & 31 & $\mathrm{~F}$ & 178 & 61 & 10 years & 5 years & IIB & 2 & 15 & $6 \cdot 5$ & 7.0 & 30 & 18 \\
\hline 11 & 27 & $F$ & 155 & 79 & 9 months & 4 months & IIA & 2 & 108 & $6 \cdot 5$ & $5 \cdot 5$ & 7 & 0 \\
\hline 12 & 58 & $\mathbf{M}$ & 200 & 74 & 4 years & 18 months & IIA & 2 & 97 & 16.0 & $7 \cdot 5$ & 0 & 3 \\
\hline 13 & 52 & $M$ & 178 & 63 & 6 months & 6 months & III & 5 & 15 & $4 \cdot 5$ & $4 \cdot 5$ & 0 & 0 \\
\hline
\end{tabular}

*Grade I, ocular; IIA, generalised mild; IIB, generalised moderate/severe; III, acute fulminating; IV, late severe." †MRC grade. ${ }^{12}+$ Normal $<9 \cdot 2$ milliseconds. ${ }^{5}$

Sniff Pdi-transdiaphragmatic pressure during maximal sniff (normal $>70 \mathrm{cmH}_{2} \mathrm{O}$ in women, $>98 \mathrm{cmH}_{2} \mathrm{O}$ in men). ${ }^{3}$

DMAP-diaphragm muscle action potential.

Studies were also performed on 16 control subjects (table 2); six were control patients with suspected diaphragmatic weakness who did not have myasthenia gravis and ten were normal subjects who gave no history of respiratory or neuromuscular disease. All the control subjects were non-smokers. Patients and subjects gave their informed consent to the procedures, which had Ethical Committee approval.

Oesophageal and gastric pressures were recorded with balloon catheter systems (PK Morgan) positioned in the mid oesophagus and stomach $^{2}$ and filled with 0.5 and $1.5 \mathrm{ml}$ air respectively. The balloon catheters were connected to Validyne differential pressure transducers (MP-45-1 $\left.\pm 150 \quad \mathrm{cmH}_{2} \mathrm{O}\right)$ and transdiaphragmatic pressure (Pdi) was obtained electrically by subtraction of oesophageal pressure from gastric pressure. Pdi at resting end expiration (FRC) was used as zero reference point. A series of ten maximal sniffs was initially performed from FRC without a noseclip and the best of the 10 sniffs was recorded to assess diaphragm contractility. ${ }^{3}$

Diaphragm muscle action potentials were recorded with surface electrodes (Nikomed $460)$ placed in the seventh or eighth intercostal spaces, $2-3 \mathrm{~cm}$ from the costal margin on either side. The skin was initially prepared with isopropyl alcohol and interelectrode resistance was kept below $10 \mathrm{k} \Omega$. A reference electrode was placed on the outer aspect of each arm. Diaphragm electromyogram (EMG) signals were processed using an amplifier (Medelec, PA63) and were filtered between 16 and 1600 Hz. Two pairs of magnetometer coils (Norman H Peterson, Boston, USA) were used to record rib cage and abdominal anteroposterior dimensions.

Phrenic nerve stimulation was performed

Table 2 Clinical features of control subjects

\begin{tabular}{|c|c|c|c|c|c|c|c|c|c|c|c|}
\hline \multirow[b]{2}{*}{ Subject } & \multirow{2}{*}{$\begin{array}{l}\text { Age } \\
\text { (years) }\end{array}$} & \multirow[b]{2}{*}{ Sex } & \multirow{2}{*}{$\begin{array}{l}\text { Height } \\
(\mathrm{cm})\end{array}$} & \multirow{2}{*}{$\begin{array}{l}\text { Weight } \\
\text { (kg) }\end{array}$} & \multirow[b]{2}{*}{ Diagnosis } & \multirow{2}{*}{$\begin{array}{l}\text { Grade } \\
\text { of } \\
\text { dyspnoea }\end{array}$} & \multirow{2}{*}{$\begin{array}{l}\text { Sniff } \\
\text { Pdi } \\
\left(\mathrm{CmH}_{2} \mathrm{O}\right)\end{array}$} & \multicolumn{2}{|c|}{$\begin{array}{l}\text { Conduction } \\
\text { time of phrenic } \\
\text { nerve }(\mathrm{ms})^{\star}\end{array}$} & \multicolumn{2}{|c|}{$\begin{array}{l}\text { Decrement of } \\
D M A P(\%)\end{array}$} \\
\hline & & & & & & & & Right & Left & Right & Left \\
\hline \multicolumn{12}{|c|}{ Control patients with diaphragm weakness: } \\
\hline $1 \mathrm{c}$ & 54 & $\mathbf{F}$ & 165 & 60 & $\begin{array}{l}\text { Systemic } \\
\text { sclerosis }\end{array}$ & 2 & 19 & $5 \cdot 5$ & 6.5 & 0 & 0 \\
\hline $2 c$ & 33 & $\mathbf{F}$ & 158 & 51 & $\begin{array}{l}\text { Spinocerebellar } \\
\text { degeneration }\end{array}$ & 2 & 35 & $7 \cdot 5$ & $7 \cdot 0$ & 2 & 2 \\
\hline $3 c$ & 46 & $\mathbf{M}$ & 173 & 71 & $\begin{array}{l}\text { Neuralgic } \\
\text { amyotrophy }\end{array}$ & 2 & 20 & $5 \cdot 6$ & $14 \cdot 6$ & 0 & 0 \\
\hline $4 c$ & 40 & $\mathbf{M}$ & 169 & 74 & $\begin{array}{l}\text { Autoimmune } \\
\text { vasculitis }\end{array}$ & 3 & 95 & $9 \cdot 0$ & $8 \cdot 0$ & 0 & 0 \\
\hline $\begin{array}{l}5 c \\
6 c\end{array}$ & 37 & $\mathbf{M}$ & 157 & 80 & Fostviral & 4 & 73 & $7 \cdot 0$ & $7 \cdot 0$ & 0 & 0 \\
\hline $\begin{array}{l}\text { 6c } \\
\text { Normal }\end{array}$ & 37 & $\mathbf{F}$ & 158 & 63 & Postviral & 2 & 58 & $7 \cdot 5$ & $7 \cdot 0$ & 0 & 0 \\
\hline \multicolumn{12}{|c|}{ Normal subjects: } \\
\hline $7 c$ & 66 & $\mathbf{F}$ & 160 & 70 & Normal & 1 & 93 & $9 \cdot 0$ & $8 \cdot 0$ & 0 & 0 \\
\hline $8 c$ & 52 & $\mathbf{M}$ & 182 & 92 & Normal & 1 & 100 & $8 \cdot 0$ & $8 \cdot 0$ & 0 & 0 \\
\hline $9 c$ & 58 & $\mathbf{M}$ & 172 & 85 & Normal & 1 & 133 & $6 \cdot 5$ & $6 \cdot 0$ & 0 & 0 \\
\hline $10 c$ & 30 & $\mathbf{M}$ & 178 & 72 & Normal & 1 & 150 & $6 \cdot 0$ & $6 \cdot 0$ & 0 & 0 \\
\hline $11 \mathrm{c}$ & 43 & $\mathbf{M}$ & 175 & 70 & Normal & 1 & 157 & $6 \cdot 5$ & $6 \cdot 5$ & 0 & 0 \\
\hline $12 \mathrm{c}$ & 41 & $\mathbf{M}$ & 175 & 65 & Normal & 1 & 146 & $7 \cdot 0$ & $6 \cdot 5$ & 0 & 0 \\
\hline $13 c$ & 39 & $\mathbf{M}$ & 179 & 83 & Normal & 1 & 145 & $7 \cdot 0$ & $7 \cdot 0$ & 0 & 0 \\
\hline $14 c$ & 38 & $\mathbf{F}$ & 156 & 58 & Normal & 1 & 145 & $6 \cdot 5$ & $5 \cdot 5$ & 7 & 7 \\
\hline $15 c$ & 30 & $\mathbf{F}$ & 160 & 50 & Normal & 1 & 120 & $6 \cdot 5$ & 6.0 & 0 & 0 \\
\hline $16 c$ & 31 & $\mathbf{F}$ & 157 & 45 & Normal & 1 & 100 & $7 \cdot 0$ & $7 \cdot 5$ & 0 & 0 \\
\hline
\end{tabular}

^Normal $<9.2$ milliseconds.

Sniff Pdi-transdiaphragmatic pressure during maximal sniff (normal $>70 \mathrm{cmH}_{2} \mathrm{O}$ in women, $>98 \mathrm{cmH}_{2} \mathrm{O}$ in men). DMAP-diaphragm muscle action potential. 
with the patient supine on a couch with one pillow. The phrenic nerves were stimulated percutaneously at the posterior border of the sternocleinomastoid muscle at the level of the cricoid cartilage. ${ }^{4} \mathrm{~A}$ bipolar surface stimulating electrode (Medelec 53054) with a tip diameter of $5 \mathrm{~mm}$ was used. The electrode was connected to a dual output Digitimer 3072 isolated stimulator which produced square wave impulses of 0.1 millisecond duration and whose frequency could be varied from 1 to $100 \mathrm{~Hz}$. The voltage of stimulation, which was increased until there was no further increase in the size of the diaphragm muscle action potential, was then raised by a further $10 \%$ to achieve supramaximal stimulation $(80-160 \mathrm{~V})$.

Each phrenic nerve was located and then stimulated in turn while the patient relaxed at FRC. In all, 10-20 diaphragm muscle action potentials were initially obtained between breaths during stimulation at $1 \mathrm{~Hz}$ to ensure that the amplitude of diaphragm muscle action potentials was stable. After a pause for several deep breaths, the patient again relaxed at FRC and held his breath for 8-15 seconds while the frequency of stimulation was increased from an initial level of $1 \mathrm{~Hz}$ to 3 or $5 \mathrm{~Hz}$ for $2-3$ seconds and was then decreased to $1 \mathrm{~Hz}$. The procedure was repeated 2-5 times during stimulation of each phrenic nerve.

Results of diaphragm muscle action potentials were displayed on a storage oscilloscope (Tektronix 5103N) and were simultaneously recorded on an ink jet pen recorder (Mingograph 800, Siemens). Recordings were also stored on an FM tape recorder (Racal Store 7) with a frequency response of up to $5000 \mathrm{~Hz}$ for later playback and analysis.

Assessment of decrement in diaphragm muscle action potentials was carried out as for limb skeletal muscles. ${ }^{1}$ The amplitudes of the first and fifth diaphragm muscle action potentials after the frequency of stimulation had been increased to $3 \mathrm{~Hz}$ were measured. The difference in size between the first and fifth potentials was expressed as a percentage of the amplitude of the first. The procedure was repeated up to three times for each phrenic nerve and the greatest fall in amplitude was recorded. An abnormal decrement in diaphragm muscle action potential amplitude was defined as a fall of $10 \%$ or more. ${ }^{1}$ Any recordings during which rib cage or abdominal magnetometer measurements altered during stimulation were rejected.

MEDICATION AND PROTOCOL

Studies were performed at least 12 hours after the last dose of anticholinesterase therapy. The phrenic nerves were located and stimulated first at $1 \mathrm{~Hz}$ and then at $3 \mathrm{~Hz}$; if no decrement in diaphragm muscle action potential amplitude occurred at $3 \mathrm{~Hz}$, the stimulation procedures were repeated at $5 \mathrm{~Hz}$. In four cases (patients 4, 6,7 , and 10) where a decrement in the size of diaphragm muscle action potentials did occur, edrophonium hydrochloride (Tensilon; 2-5 $\mathrm{mg}$ ) was then administered intravenously and the stimulation procedures were repeated within 1-3 minutes.

\section{Results}

Sniff Pdi was reduced in six of the 13 patients with myasthenia gravis (patients $6,8,9,10$, 12,13 ; table 1) and in the six control patients with suspected diaphragmatic weakness that was not due to myasthenia gravis (patients 1c6c; table 2). Sniff Pdi was normal in all ten normal subjects, confirming normal diaphragm strength (subjects 7c-16c; table 2).

Phrenic nerve stimulation was well tolerated by all patients and controls and both phrenic nerves were successfully stimulated in all cases. Phrenic nerve conduction time was normal in all patients with myasthenia gravis except patient 12 , who had had a right phrenic nerve crush for tuberculosis; his phrenic nerve conduction time was prolonged to 16.0 milliseconds on the right side. Conduction time was also prolonged on the left side $(14.6$ milliseconds) in patient $3 c$ with neuralgic amyotrophy (table 2) but was normal in the remaining five patients with diaphragm weakness and in all ten normal subjects (7c-16c). After a short learning phase (3-4 breaths), patients and subjects were able to maintain their lung volume as instructed at FRC during stimulations; rib cage and anteroposterior dimensions did not alter during stimulations in any of the recordings that were analysed. The amplitude of diaphragm muscle action potentials during stimulation at $1 \mathrm{~Hz}$ varied between 0.8 and 1.4 $\mathrm{mV}$; although diaphragm muscle action potential amplitude varied between patients it was stable within any one patient.

Five patients with myasthenia gravis showed consistent decrements in the amplitude of diaphragm muscle action potential during stimulation at $3 \mathrm{~Hz}$ (patients 4, 6, 7, 9, 10; table 1). A decrement during the first four or five responses was followed by a slight enlargement of the diaphragm muscle action potential, and when stimulation frequency returned to $1 \mathrm{~Hz}$ recovery occurred within four or five responses. A typical example of such a response is shown in the figure. Reductions in diaphragm muscle action potentials of both phrenic nerves of $18-43 \%$ were demonstrated during stimulation in three patients (patients 4, 6, 10). Reductions of $15 \%$ and $19 \%$ were seen in two patients (patients 7 and 9) during stimulation of one phrenic nerve only, and an insignificant decrement $(<10 \%)$ was seen during stimulation of the other nerve. No decrement was seen during stimulation of either nerve at 3 or $5 \mathrm{~Hz}$ in the remaining eight patients with myasthenia gravis.

Of the four patients who showed decrement, this reduction in diaphragm muscle action potentials was less marked in three patients after Tensilon; decrement in diaphragm muscle action potential was reduced from $26 \%$ to $15 \%$ for the right phrenic nerve in patient 6 , from $19 \%$ to $9 \%$ on the right in patient 7 , and from $30 \%$ to $19 \%$ on the right and from $18 \%$ to $16 \%$ on the left in patient 10 . There was no reduction in the decrement of diaphragm muscle action potential amplitude in patient 4 following Tensilon.

No decrement was seen in the amplitude of diaphragm muscle action potentials during 


\section{A Myasthenia gravis}

(R) Diaphragm EMG

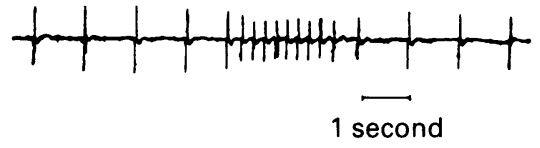

I $400 \mu \mathrm{v}$

1 second

(L) Diaphragm EMG

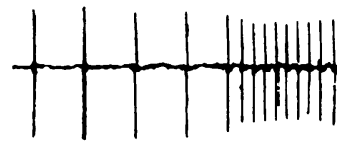

B Normal subject

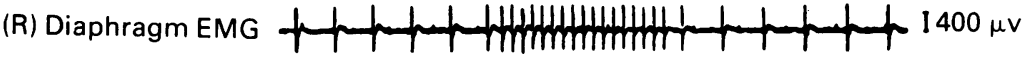

1 second

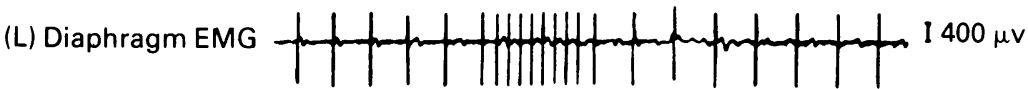

Transcutaneous phrenic nerve stimulation. (A) Patient with myasthenia gravissignificant decrement occurred in the size of both right $(R)$ and left $(L)$ diaphragm muscle action potentials (Diaphragm EMG) when stimulation frequency increased above $1 \mathrm{~Hz}$. (B) Normal subject-no decrement occurred in the size of diaphragm muscle action potentials (Diaphragm EMG) at increased frequencies of stimulation.

phrenic nerve stimulation at increased frequencies in any of the patients with diaphragm weakness who did not have myasthenia gravis (patients 1c-6c; table 2) or in any of the normal subjects (subjects $7 c-16 c$; table 2 ). A typical example of stimulation in a normal subject is shown in the figure.

\section{Discussion}

Although patients with myasthenia gravis in this study were a selected group in that they all complained of exertional breathlessness, with two exceptions they all had clinically mild to moderate disease. Thus phrenic nerve stimulation was performed to see whether their breathlessness could be related to myasthenia gravis. We found that abnormalities of neuromuscular transmission in the diaphragm were detected in five of 13 myasthenic patients during repetitive stimulation of the phrenic nerves at frequencies of $1-5 \mathrm{~Hz}$. Although diaphragm muscle action potentials have been reported to vary between subjects and between days, ${ }^{5}$ the stability of the amplitude of diaphragm muscle action potential, usually recorded within a subject during stimulation at $1 \mathrm{~Hz}$ as in these studies (figure), allowed a decrease in amplitude of $10 \%$ or more to be assessed reliably. A decremental response was seen in five of the 13 patients with myasthenia gravis. This confirms that the diaphragm is similar to other skeletal muscles in that abnormalities of neuromuscular transmission can be detected.

We were confident that the reduction in the amplitude of diaphragm muscle action potential during stimulation at higher frequencies was not due to a change in the relationship of the stimulating electrode to the phrenic nerve. An initial period of stimulation was performed at $1 \mathrm{~Hz}$ to ensure that the position of stimulating electrodes on the phrenic nerves was stable and that the amplitude of diaphragm muscle action potentials was constant.

Consistent pressure was applied to the electrode throughout the stimulation procedures to minimise movement of the electrode. Furthermore, the decrease, followed by a slight increase, in the amplitude of diaphragm muscle action potential was typical of the pattern seen in myasthenia during stimulation of an affected peripheral nerve. The mechanism underlying this post-tetanic potentiation is unclear but is thought to be related to a build up of calcium in the presynaptic terminal, which allows short term facilitation of the shock. If stimulation were to continue for longer, failure of transmission would eventually occur. Since the fifth (or fourth) shock is the lowest point generally found, this is the one that is compared with the first when limb skeletal muscles are being studied and the one that we measured in our patients. Finally, magnetometers were used to ensure that rib cage and abdominal anteroposterior dimensions remained constant at FRC during the stimulations. This made it unlikely that alterations in lung volume, and hence in the position of the diaphragm with respect to the recording electrodes, could have accounted for the observed decrement in muscle action potentials. In addition, the finding that no decrement was seen in the control subjects, and that decrement was reversed in the myasthenic patients following Tensilon, further supported the suggestion that this was a true finding and not caused by a change in position of the recording electrode with respect to the diaphragm.

Although the pattern of affected muscles in myasthenia gravis is variable, certain muscles are characteristically involved in many cases. Weakness of facial, pharyngeal, or lingual muscles is an early manifestation in $12-20 \%$ of patients and occurs eventually in $80-90 \%{ }^{6}$ The diaphragm is the principal muscle of respiration, being responsible for over two thirds of inspiration during quiet breathing; weakness of the diaphragm and intercostal muscles has been reported to be rare $(1-4 \%)$ in the early stages of disease but later becomes clinically significant in $50-60 \% .^{7}$ The onset of ventilatory failure varies from the start of the illness to over 25 years after the start of myasthenic symptoms. ${ }^{8}$

Previous workers have reported a decremental response in $95 \%$ of patients with myasthenia gravis in whom the deltoid and two other muscles were tested ${ }^{1}$ but lower diagnostic yields are often found in practice. Although anticholinesterase medication need not be stopped before such studies, results are more frequently diagnostic if therapy is discontinued as was done in these studies. Nevertheless, even when weakness and fatiguability are clinically present in a proximal limb muscle, a decremental response is not always seen during repetitive stimulation at increased frequencies owing to problems of sampling. Similarly, we found that a decrease in the amplitude of diaphragm muscle action potential was not present in three 
of the patients with myasthenia, two (patients 8 and 12) who had very mild and one (patient 13) who had severe diaphragmatic involvement on the basis of reduced sniff Pdi. Thus repetitive stimulation of the phrenic nerves, as with peripheral nerves, appears not always to be sensitive in detecting abnormalities of neuromuscular transmission. Although long term anticholinesterase therapy can produce a myopathy like process and abnormal EMG findings due to chronic overstimulation of the acetylcholine receptors that are still functioning, we did not feel that this was the explanation for our results; our EMG findings were characteristic of the specific pattern found in limb skeletal muscles that are involved in myasthenia.

Various provocative measures including exercise, ischaemia, and regional curare have been proposed to increase the frequency of producing a decremental response during stimulation in distal muscles. Higher stimulation rates of more than $5 \mathrm{~Hz}$ have not been found to be helpful. It is possible that manoeuvres designed to induce diaphragmatic fatigue might have increased the diagnostic yield in our patients, but we aimed to develop a simple protocol that would be easy to perform in patients.

A positive response to anticholinesterase agents is sometimes included in the definition of myasthenia gravis; anticholinesterase drugs are known to produce a reduction in the degree of decrement of compound muscle action potentials evoked during repetitive stimulation of a peripheral nerve. Similarly, we noted a partial temporary reversal of fatiguability during stimulation of the phrenic nerves after Tensilon in three patients. Nevertheless, a failure to respond to anticholinesterase agents is well recognised in purely ocular myasthenia and, although less usual, may also occur in patients with more generalised myasthenia. ${ }^{9}$ Thus our findings in the diaphragm are not inconsistent with those for other skeletal muscles.

Acute respiratory failure occurred in one patient (patient 6) seven days after these studies showed a decremental response of both phrenic nerves during stimulation. Two further patients (patients 9 and 10), who also showed decremental responses on stimulation, had been ventilated previously on two and three separate occasions respectively. Thus it seems that the respiratory muscles were affected in these three patients, who all had reduced sniff Pdi values and who showed a significant decrease in diaphragm muscle action potential during phrenic nerve stimulation. This respiratory muscle weakness could not have been detected on the basis of symptoms alone, as dyspnoea was not worse in these patients than in the eight patients who showed no decrement (table 1). Previous studies have also shown that dyspnoea alone is a poor predictor of the severity of a patient's diaphragmatic weakness. ${ }^{10}$

It was relevant that patient 4 had required ventilation four years previously but now had a normal sniff Pdi. She nevertheless still showed a decrement in the amplitude of diaphragm muscle action potential on repetitive stimulation, suggesting that although able to generate pressures that lay within the normal range she still had diaphragmatic weakness. Thus both Pdi measurement and phrenic nerve stimulation when performed in combination may provide more information about diaphragmatic weakness in myasthenia gravis than when either test is performed alone.

Abnormalities of neuromuscular transmission in the diaphragm can be detected during phrenic nerve stimulation. False negative results do occur but repetitive stimulation of the phrenic nerves may be a useful and noninvasive procedure that can be performed in myasthenia gravis when weakness of the diaphragm is suspected.

We are grateful to Dr C W Havard for allowing us to study patients under his care. Anne Mier was supported by the Medical Research Council of the UK and Conor Brophy by Napp Laboratories.

Ozdemir $C$ Young $R$. The results to be expected from electrical testing in the diagnosis of myasthenia gravis. Ann NY Acad Sci 1976;174:203-22.

2 Agostoni E, Rahn H. Abdominal and thoracic pressures at different lung volumes. $J$ Appl Phys 1960;15: 1087-92.

3 Miller J, Moxham J, Green M. The maximal sniff in the assessment of diaphragm dysfunction in man. Clin $\mathrm{Sci}$ 1985;69:91-6.

4 Sarnoff SJ, Sarnoff LC, Whittenberger J. Electrophrenic respiration VII. The motor point of the phrenic nerve in relation to external stimulation. Surg Gynecol Obstet 1951;93:190-6.

5 Newsom Davis J. Phrenic nerve conduction in man. J Neurol Neurosurg Psychiatry 1967;30:420-6.

6 Kaminski M, Young R. Neuromuscular and neurological disorders affecting respiration. In: Roussos C, Macklem P eds. The Thorax. New York, Basel: Marcel Dekker, 1982:1023-87.

7 Simpson JA. Myasthenia gravis and myasthenic syndromes. In: Walton JN, ed. Disorders of voluntary muscle, 4th edn. Edinburgh: Churchill Livingstone, 1981:585-624.

8 Ferguson $\mathrm{P}$, Murphy R, Lascelles R. Ventilatory failure in myasthenia gravis. J Neurol Neurosurg Psychiatry 1982;45:217-22.

9 Perlo VP, Poskanzer D, Schwab R, Viets H, Osserman K, Genkins G. Myasthenia gravis: evaluation of treatment in 1355 patients. Neurology (Minneapolis) 1966;16:431.

10 Mier-Jedrzejowicz A, Brophy C, Moxham J, Green M. Assessment of diaphragm weakness. Am Rev Respir Dis 1988;137:877-83.

11 Osserman K. Myasthenia gravis. New York: Grune and Stratton, 1958.

12 McGavin CR, Artvinli M, Naoe H, McHardy G. Dyspnoea, disability and distance walked: comparison of estimates of exercise performance in respiratory disease. $B M J$ 1978;ii:241-3. 